\title{
Correlation between TRAIL and caspase-8 expression and their relationship with cell proliferation and apoptosis in human osteosarcoma
}

\author{
X. Ning, X.W. Shang, Y. Zhuang, M. Liu, H. Yang, H. Zhang and \\ M.Z. Huang \\ Department of Orthopedics, \\ The Affiliated Hospital of Guizhou Medical University, Guiyang, Guizhou, China \\ Corresponding author: $\mathrm{X}$. Ning \\ E-mail: xuning221@sina.com
}

Genet. Mol. Res. 15 (4): gmr15048876

Received June 13, 2016

Accepted August 26, 2016

Published December 19, 2016

DOI http://dx.doi.org/10.4238/gmr15048876

Copyright $(2016$ The Authors. This is an open-access article distributed under the terms of the Creative Commons Attribution ShareAlike (CC BY-SA) 4.0 License.

\begin{abstract}
Osteosarcoma is a common malignant bone tumor that mainly affects children and adolescents. Tumor necrosis factor-related apoptosis-inducing ligand (TRAIL) is a member of the tumor necrosis factor superfamily. Caspase- 8 appears in the upstream of apoptosis signaling pathway among caspases. We investigated TRAIL and caspase- 8 levels in osteosarcoma patients to determine their correlation with cell proliferation and apoptosis. Osteosarcoma and osteochondroma patients receiving surgery in our hospital were selected. TRAIL and caspase-8 expression levels in tissue were determined by immunohistochemistry, and protein levels in cells were evaluated by western blotting. Human osteosarcoma cell viability was determined by 3-(4,5-dimethylthiazol2-yl)-2,5-diphenyltetrazolium bromide (MTT) assay. The osteosarcoma
\end{abstract}


and osteochondroma cell cycles and apoptosis were investigated by flow cytometry. Correlation analysis was applied to TRAIL and caspase-8 levels during cell apoptosis. Positive TRAIL and caspase- 8 expression rates in osteosarcoma tissue were significantly lower than in the controls $(\mathrm{P}<0.05)$. TRAIL $(0.114 \pm 0.002)$ and caspase-8 $(0.352 \pm 0.124)$ levels in experimental cells were obviously lower than in the controls $(\mathrm{P}<$ $0.05)$. Osteosarcoma cells in the experimental group demonstrated higher proliferation and lower apoptosis at 24,48 , and $72 \mathrm{~h}(\mathrm{P}<0.05)$. The experimental cell number increased in the G1 stage and decreased in the $\mathrm{S}$ stage $(\mathrm{P}<0.05)$. TRAIL and caspase- 8 proteins showed positive correlation with apoptosis in osteosarcoma $(\mathrm{P}<0.05)$. Human osteosarcoma presented reduced TRAIL and caspase- 8 levels with enhanced cell proliferation and reduced apoptosis. TRAIL and caspase- 8 expression levels were positively correlated with apoptosis in osteosarcoma.

Key words: TRAIL; Caspase-8; Osteosarcoma

\section{INTRODUCTION}

Osteosarcoma mostly appears in children and adolescents. It is a common malignant bone tumor accounting for $8.9 \%$ of all cancer deaths. Adjuvant and neoadjuvant chemotherapies for osteosarcoma have been extensively developed and applied in clinical settings in recent years, greatly increasing the survival rate. However, owing to the side effects and serious toxicity of chemotherapy drugs, many patients do not complete chemotherapy, which leads to tumor recurrence and metastasis. Amputation is necessary in many patients, and the prognosis is poor (Wafa and Grimer, 2006). Osteosarcoma cell proliferation is related to an imbalance in apoptosis, which results in malignant hyperplasia (Ottaviani and Jaffe, 2009). Tumor necrosis factor-related apoptosis-inducing ligand (TRAIL) is a type-II transmembrane protein. It has a homologous trimer subunit structure at the extracellular domain C-terminal that can be hydrolyzed from the cell surface by a specific protease to form a soluble TRAIL monomer. TRAIL is widely expressed in the spleen, thymus, small intestine, colon, placenta, ovaries, and prostate, but not in the brain, liver, or testes. TRAIL is important because it participates in the induction of tumor cell apoptosis, although it has no effect on normal cells (Bellail et al., 2009). Caspases-8 is an important protease that is involved in regulating cell apoptosis (Shabanzadeh et al., 2015). Death receptor activation can trigger caspase- 8 , which directly activates effector caspase- 3 through a FAS-related protein, thereby inducing apoptosis. The proteins belonging to the caspase family are the main executors of apoptosis; caspase- 8 is an initiator caspase that plays an important role in death receptor-mediated cell apoptosis. In this study, we collected tissue for cell isolation from selected osteosarcoma patients. We determined TRAIL and caspase-8 levels, and evaluated cell proliferation and apoptosis for correlation analysis.

\section{MATERIAL AND METHODS}

\section{Material}

\section{General information}

We selected a total of 30 osteosarcoma patients who had received surgical treatment

Genetics and Molecular Research 15 (4): gmr15048876 
between January 2014 and January 2015 at the affiliated hospital of Guizhou Medical University. They comprised 16 males and 14 females with a mean age of $51.2 \pm 3.3$ years (20-70 years). Another 30 osteochondroma patients who had received surgery in the corresponding period at the same hospital were enrolled as controls. They comprised 15 males and 15 females with a mean age of $49.7 \pm 4.1$ years (25-70 years). Surgical specimens from the tumor surfaces and section areas were diagnosed by two pathologists. No significant differences in age, height, or weight existed between the two groups $(\mathrm{P}>0.05)$.

The inclusion criteria were: diagnosis by pathology; absence of connective tissue disease or immune system disease; absence of serious liver disease, renal disease, or autoimmune disease; normal blood routine, urine routine, liver function, and renal function; and no history of radiotherapy, chemotherapy, immunotherapy, freezing, or laser treatment.

The study protocol was approved by the Research Ethics Committee of the affiliated hospital of Guizhou Medical University, and all patients gave their informed consent before study commencement.

\section{Reagents and instruments}

Rabbit antihuman TRAIL and caspase-8 polyclonal antibodies, an SP general kit, a DAB kit, polylysine, citric acid antigen retrieval buffer, phosphate-buffered saline (PBS), hydrogen peroxide, xylene, anhydrous ethanol, paraffin wax, hematoxylin, and neutral balsam were obtained from ZSBio (Beijing, China). Dulbecco's modiðed Eagle's medium (DMEM), penicillin-streptomycin, and fetal bovine serum (FBS) were obtained from Gibco. Trizol reagent was obtained from Invitrogen.

The following is a list of the instruments used in this study: a Benchtop (Formal 205, USA) inverted microscope (Olympus, Japan), a tissue-embedding machine (Sakura, Japan), a dehydrator (Tiyoda, Japan), an ultramicrotome (Leica, Germany), a thermostatic oscillator (Jinghong, China), electric HCB-Turn equipment (Shanghai Shengxin Scientific Instruments Co., Ltd., China), a computer image analysis system (Hewlett-Packard, USA), an incubator (Thermo Fisher Scientific, USA), a carbon dioxide incubator and a $-80^{\circ} \mathrm{C}$ refrigerator (Sanyo Electric Co., Ltd., USA), and a low-temperature, high-speed centrifuge (Beckman Coulter Inc., USA).

\section{Experimental methods}

\section{Cell isolation and cultivation}

Osteosarcoma and osteochondroma tissue samples from patients were cut into pieces and soaked in a solution containing penicillin-streptomycin for 15 min under aseptic conditions. After washing with Hank's buffer, the tissue was digested with 1\% collagenase for $20 \mathrm{~min}$. The supernatant was removed and the reaction was stopped with DMEM and 10\% FBS. The cells were suspended in DMEM containing $10 \% \mathrm{FBS}$ at $10^{4} / \mathrm{mL}$ and cultured in $5 \% \mathrm{CO}_{2}$ at $37^{\circ} \mathrm{C}$. The cells were then passaged at 1:2 every other day, investigated using a microscope, and counted.

\section{Immunohistochemistry}

The tissue was fixed in formalin and subjected to dehydration, hyalinization, embedding, sectioning, dewaxing, dehydration, and high-pressure heat repair. Next, the tissue

Genetics and Molecular Research 15 (4): gmr15048876 
was blocked with $3 \%$ hydrogen peroxide for $10 \mathrm{~min}$, and sealed with goat serum at room temperature for $10 \mathrm{~min}$. After incubation in $50 \mu \mathrm{L}$ primary antibody at room temperature for 1 $\mathrm{h}$, the sections were further incubated in $50 \mu \mathrm{L}$ secondary antibody for $10 \mathrm{~min}$. Finally, $50 \mu \mathrm{L}$ streptavidin-peroxidase was added to the sections for $10 \mathrm{~min}$. After dying with hematoxylin and eosin (H\&E) and differentiating with hydrochloric acid/alcohol solution, the sections were investigated using a microscope.

\section{Western blotting}

Osteosarcoma and osteochondroma cells in the logarithmic phase were collected to extract protein. The protein was separated by $8 \%$ sodium dodecyl sulfate polyacrylamide gel electrophoresis (SDS-PAGE). After blocking at room temperature for $1 \mathrm{~h}$, the membrane was incubated in primary antibody $(1: 200, \beta$-actin $1: 500)$ at $4^{\circ} \mathrm{C}$ overnight. The membrane was then washed with TBS-T solution and incubated in secondary antibody $(1: 2000)$ for $1 \mathrm{~h}$. The membrane was developed by chemiluminescence and analyzed using the Quantity One software. The experiment was repeated twice.

\section{3-(4,5-dimethylthiazol-2-yl)-2,5-diphenyltetrazolium bromide (MTT) assay}

Osteosarcoma and osteochondroma cells in the logarithmic phase were cultured in $2 \%$ FBS for $24 \mathrm{~h}$, then cultured in DMEM with $10 \%$ FBS. After adding $20 \mu \mathrm{L}$ MTT solution (5 $\mathrm{mg} / \mathrm{mL}$ ), the cells were further cultured for $4 \mathrm{~h}$. The plate was read at $570 \mathrm{~nm}$ after adding 150 $\mu \mathrm{L}$ dimethyl sulfoxide for $10 \mathrm{~min}$. The experiment was repeated twice.

\section{Flow cytometry}

An Annexin V-FITC detection kit was used to determine the rate of cell apoptosis. The cells were digested and collected at 106/L. Next, $490 \mu \mathrm{L}$ buffer, $5 \mu \mathrm{L}$ Annexin V-FITC, and $5 \mu \mathrm{L}$ propidium iodide (PI) were added to the cells, which were kept in the dark for $10 \mathrm{~min}$. The cell cycle and apoptosis rates were investigated by flow cytometry. The experiment was repeated twice.

\section{Judgment standard}

A known positive sample slice was used as the positive control, and PBS instead of the primary antibody was used as the negative control. The H\&E-stained slices were examined.

A sample was judged to be positive for TRAIL and caspase-8 if brown or tan particles were present in the cell membrane or cytoplasm instead of the nucleus. Staining was graded as follows: negative (-), stained cell number $\leq 10 \%$; weak positive (+), stained cell number 11$25 \%$; positive $(++)$, stained cell number $26-50 \%$; and strong positive $(+++)$, stained cell number $>50 \%$. Five fields in each slice were randomly selected for image analysis and recording.

\section{Statistical analysis}

All data analysis was performed using the SPSS 17.0 software. The data are reported as means \pm standard deviation. Enumeration data were compared using the chi-square test, 
whereas measurement data were compared using the $t$-test. The correlation test was performed using logistic analysis. $\mathrm{P}<0.05$ was considered statistically significant.

\section{RESULTS}

\section{TRAIL and caspase-8 expression in tissue}

Immunohistochemistry was performed to detect TRAIL and caspase- 8 expression in osteosarcoma tissue, in para-carcinoma tissue, and in the controls. The results showed that TRAIL and caspase- 8 proteins were present in the cytoplasm in osteosarcoma and osteochondroma tissue. TRAIL and caspase- 8 positive expression rates in the osteosarcoma tissue, para-carcinoma tissue, and the controls were 7.5 and $13.3 \%, 13.3$ and $16.7 \%$, and 50 and $80 \%$, respectively. TRAIL and caspase- 8 positive expression rates in the osteosarcoma tissue were significantly lower than in the controls $(\mathrm{P}<0.05)$ (Table 1 and Figure 1$)$.

Table 1. TRAIL and caspase-8 expression in tissue detected by immunohistochemistry.

\begin{tabular}{l|c|c|c|c|c|c|c|c|c}
\hline Group & Cases & \multicolumn{4}{|c|}{ Trail } & \multicolumn{4}{c}{ Caspase-8 } \\
\hline Experimental group & & - & +-++ & +++ & Positive rate & - & +-++ & +++ & Positive rate \\
\hline Osteosarcoma tissue & 30 & 27 & 3 & 0 & $7.5 \%^{* *}$ & 26 & 4 & 0 & $13.3 \% *^{* \#}$ \\
\hline Para-carcinoma tissue & 30 & 26 & 4 & 0 & $13.3 \%^{\&}$ & 25 & 5 & 0 & $16.7 \%^{\&}$ \\
\hline Control & 30 & 15 & 10 & 5 & $50 \%$ & 6 & 3 & 21 & $80 \%$ \\
\hline
\end{tabular}

TRAIL $=$ tumor necrosis factor-related apoptosis-inducing ligand; $* \mathrm{P}<0.05$, compared with para-carcinoma tissue; ${ }^{\#} \mathrm{P}<0.05$, compared with control; ${ }^{\mathrm{P}}<0.05$, compared with control.

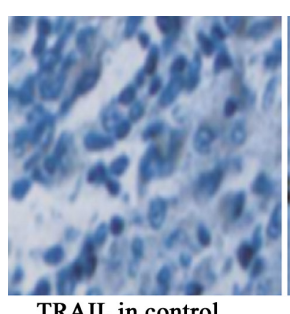

TRAIL in control

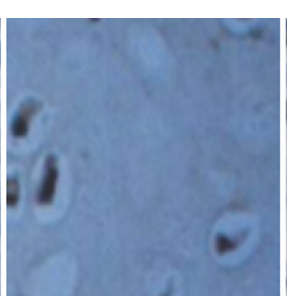

TRAIL in experimental

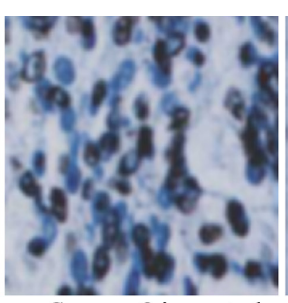

Caspase-8 in control Capase-8 in experimental

Figure 1. Tumor necrosis factor-related apoptosis-inducing ligand (TRAIL) and caspase- 8 expression in tissue detected by immunohistochemistry.

\section{TRAIL and caspase-8 protein levels in cells}

Western blotting showed that TRAIL protein $(0.114 \pm 0.002)$ and caspase- 8 protein $(0.352 \pm 0.124)$ levels in the experimental cells were obviously lower than in the controls ( $\mathrm{P}$ $<0.05$ ) (Table 2 and Figure 2).

Table 2. TRAIL and caspase-8 expression in cells.

\begin{tabular}{l|c|c}
\hline Group & Trail & Caspase-8 \\
\hline Control & $0.892 \pm 0.011$ & $0.787 \pm 0.016$ \\
\hline Experimental group & $0.114 \pm 0.002^{*}$ & $0.252 \pm 0.124^{*}$ \\
\hline
\end{tabular}

TRAIL = tumor necrosis factor-related apoptosis-inducing ligand; $* \mathrm{P}<0.05$, compared with control. 


\section{TRAIL \\ Caspase-8 \\ $\beta$-actin \\ Experimental group

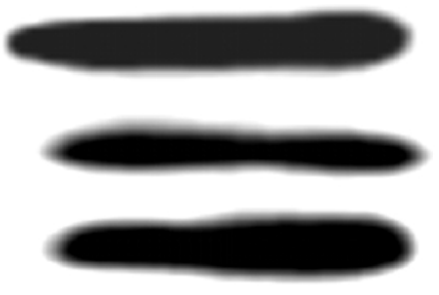 \\ Control}

Figure 2. Tumor necrosis factor-related apoptosis-inducing ligand (TRAIL) and caspase-8 expression in cells.

\section{Cell viability compared by MTT assay}

Human osteosarcoma cell in the experimental group demonstrated higher proliferation at 24,48 , and $72 \mathrm{~h}$ compared with the controls $(\mathrm{P}<0.05)$ (Table 3$)$.

\section{Table 3. Cell viability compared by MTT assay.}

\begin{tabular}{l|c|c|c}
\hline Group & $24 \mathrm{~h}$ & $48 \mathrm{~h}$ & $72 \mathrm{~h}$ \\
\hline Control & $0.125 \pm 0.012$ & $0.151 \pm 0.045$ & $0.223 \pm 0.051$ \\
\hline Experimental group & $0.106 \pm 0.153^{*}$ & $0.122 \pm 0.028^{* \#}$ & $0.996 \pm 0.026^{* * \&}$ \\
\hline
\end{tabular}

MTT = 3-(4,5-dimethylthiazol-2-yl)-2,5-diphenyltetrazolium bromide; *P $<0.05$, compared with control; ${ }^{*} \mathrm{P}<$ 0.05 , compared with $24 \mathrm{~h}$; ${ }^{\&} \mathrm{P}<0.05$, compared with $48 \mathrm{~h}$.

\section{Human osteosarcoma and osteochondroma cell cycle and apoptosis rate comparison}

An Annexin V-FITC detection kit was used to determine the human osteosarcoma and osteochondroma cell apoptosis rate. The results demonstrated that the cell apoptosis rate in the experimental group was obviously lower than in the control $(\mathrm{P}<0.05)$ (Table 4).

Table 4. Cell apoptosis rate detected by Annexin V-FITC.

\begin{tabular}{l|c|c|c|c}
\hline \multirow{2}{*}{ Group } & \multicolumn{4}{|c}{ Cell apoptosis rate (\%) } \\
\cline { 2 - 5 } & Quadrant 1 & Quadrant 2 & Quadrant 3 & Quadrant 4 \\
\hline Control & 2.4 & 23.5 & 37.9 & 43.2 \\
\hline Experimental & $0.7^{*}$ & $2.2^{*}$ & $73.8^{*}$ & $10.3^{*}$ \\
\hline
\end{tabular}

$* \mathrm{P}<0.05$, compared with control.

Cell cycle detection revealed that the experimental cell number increased in the G1 stage and decreased in the $\mathrm{S}$ stage compared with the control $(\mathrm{P}<0.05)$ (Table 5 and Figure 3 ).

Table 5. Cell cycle changes detected by flow cytometry.

\begin{tabular}{l|c|c|c|c|c}
\hline \multirow{2}{*}{ Group } & \multicolumn{3}{|c|}{ Cell cycle } & \multirow{2}{*}{ Apoptotic peak } & Apoptosis index \\
\cline { 2 - 4 } & G1 & S & G2/M & & \\
\hline Control & $74.7 \pm 0.5$ & $18.7 \pm 1.3$ & $7.6 \pm 1.1$ & 0 & $24.5 \pm 2.5$ \\
\hline Experimental group & $92.6 \pm 1.2^{*}$ & $7.6 \pm 0.8^{*}$ & $0.3 \pm 0.7^{*}$ & $1.1 \pm 0.5^{*}$ & $17.8 \pm 1.8^{*}$ \\
\hline
\end{tabular}

$* \mathrm{P}<0.05$, compared with control.

Genetics and Molecular Research 15 (4): gmr15048876 

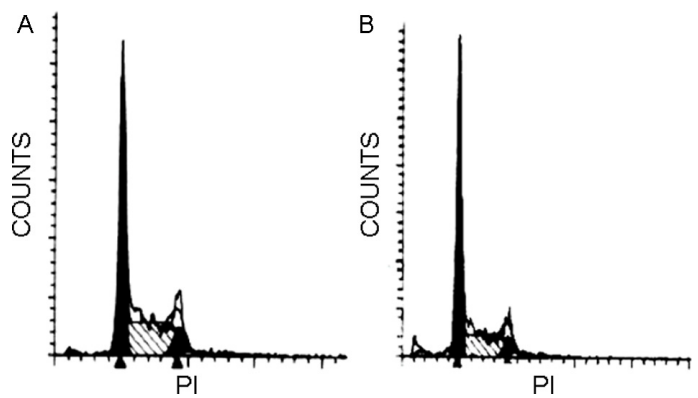

Figure 3. Cell cycle changes detected by flow cytometry. A. Experimental group; B. control group.

\section{TRAIL and caspase- 8 correlation with apoptosis rate in osteosarcoma}

Correlation analysis showed that TRAIL was positively correlated with caspase-8 protein $(\gamma=0.799, \mathrm{P}<0.01)$. TRAIL and caspase- 8 proteins showed positive correlation with apoptosis in osteosarcoma $(\gamma=0.596, \mathrm{P}<0.01 ; \gamma=0.547, \mathrm{P}<0.01)$.

\section{DISCUSSION}

Tumor occurrence and development is related to unlimited and uncontrollable cell proliferation. The purpose of malignant tumor treatment is to selectively trigger tumor cell death (Hanahan and Weinberg, 2000). Because malignant tumors constantly strive to prevent cell death and survive, the process often leads to apoptosis resistance and chemotherapy resistance (Sharifi et al., 2015). TRAIL is an important member of the tumor necrosis factor superfamily that can induce tumor cell apoptosis. It has a lethal effect on tumor cells but has no significant toxic effect on normal cells (Zhao et al., 2012). Caspase- 8 is a cysteine protease that is mainly expressed in bone and cartilage tissues and cells. It has a death effect domain that can bind with the Fas-associated protein with death domain (FADD), enabling its participation in cell apoptosis (Kavanagh et al., 2015; Polanski et al., 2015).

In this study, we selected osteosarcoma and osteochondroma patients that had received surgery in our hospital, and detected TRAIL and caspase- 8 expression in their tissues. The study showed that TRAIL and caspase- 8 are widely distributed in osteosarcoma, but locally distributed in osteochondroma. The TRAIL and caspase- 8 positive expression rates in osteosarcoma tissue, in para-carcinoma tissue, and in the controls were 7.5 and $13.3 \%, 13.3$ and $16.7 \%$, and 50 and $80 \%$, respectively. The TRAIL and caspase- 8 positive expression rates in osteosarcoma tissue were significantly lower than in the controls. Western blotting revealed that TRAIL protein and caspase- 8 protein levels in the experimental cells were obviously lower than in the controls. This suggests that TRAIL and caspase- 8 expression decreased in osteosarcoma. Previous studies have demonstrated that TRAIL participates in multiple tumor cell apoptosis without affecting normal cells, including in the gastrointestinal tract, breast, and lung (Soria et al., 2010). Basic research has revealed that TRAIL targets five receptors, one of which is the death receptor expressed in tumor cells, and it can induce apoptosis by binding with that receptor. In contrast, when TRIAL binds to the decoy receptor that is mainly expressed in normal cells, apoptosis may not occur (Dorsey et al., 2009; Na et al., 2010; Piras et al., 2011). Because its effect on cells depends on the distribution of the receptors,

Genetics and Molecular Research 15 (4): gmr15048876 
TRAIL has a unique antitumor function (Chen et al., 2010). Caspase enzymes are involved in cell apoptosis; they deliver apoptosis signals and regulate the effects of apoptosis. Caspase- 8 can form a death-inducing signaling complex that plays an important role in apoptosis by reflecting the levels of trigger factors and cell apoptosis (Kang et al., 2015; Qi et al., 2015).

In this study, we isolated osteosarcoma and osteochondroma cells from tissue. The MTT assay revealed that human osteosarcoma cell proliferation in the experimental group increased at 24, 48, and $72 \mathrm{~h}$. Annexin V-FITC detection showed that the cell apoptosis rate in the experimental group was obviously lower than in the controls. Flow cytometry demonstrated that the experimental cell number increased in the G1 stage and decreased in the S stage compared with the controls. The authors of a previous study reported that TRAIL protein is downregulated in osteosarcoma, indicating that deletion of the TRAIL gene may occur, leading to decreased receptor binding and promotion of osteosarcoma (Himeji et al., 2002). The destructive effect of TRAIL on CHP212 and SY5Y cells is reduced after adding caspase- 8 inhibitor, suggesting that TRAIL-induced cell apoptosis is regulated by caspase- 8 (Yang and Thiele, 2003). Caspase- 8 downregulation prevents TRAIL-induced apoptosis in glioblastoma cell line SC189 (Woods et al., 2008; Bellail et al., 2010).

In this study, we examined the correlation between TRAIL and caspase- 8 expression and their relationship with cell apoptosis in osteosarcoma patients. TRAIL was positively correlated with caspase- 8 protein, and TRAIL and caspase- 8 proteins showed positive correlation with apoptosis in osteosarcoma.

In brief, TRAIL and caspase- 8 expression decreased in human osteosarcoma, resulting in increased cell proliferation, elevated numbers of cells in the G1 stage, decreased numbers of cells in the S stage, inhibition of transition from the G1 stage to the S stage, and reduced cell apoptosis. TRAIL and caspase- 8 play important roles in the occurrence, development, and prognosis of osteosarcoma. Further in-depth investigation to confirm the specific signaling pathway mechanism between TRAIL and caspase- 8 would provide a more detailed theoretical basis for the improvement of the early diagnosis and treatment of osteosarcoma.

\section{Conflicts of interest}

The authors declare no conflict of interest.

\section{ACKNOWLEDGMENTS}

We thank the anonymous reviewers for reviewing this manuscript.

\section{REFERENCES}

Bellail AC, Qi L, Mulligan P, Chhabra V, et al. (2009). TRAIL agonists on clinical trials for cancer therapy: the promises and the challenges. Rev. Recent Clin. Trials 4: 34-41. http://dx.doi.org/10.2174/157488709787047530

Bellail AC, Tse MC, Song JH, Phuphanich S, et al. (2010). DR5-mediated DISC controls caspase-8 cleavage and initiation of apoptosis in human glioblastomas. J. Cell. Mol. Med. 14 (6A): 1303-1317. http://dx.doi.org/10.1111/j.15824934.2009.00777.x

Chen J, Sun X, Yang W, Jiang G, et al. (2010). Cisplatin-enhanced sensitivity of glioblastoma multiforme U251 cells to adenovirus-delivered TRAIL in vitro. Tumour Biol. 31: 613-622. http://dx.doi.org/10.1007/s13277-010-0077-x

Dorsey JF, Mintz A, Tian X, Dowling ML, et al. (2009). Tumor necrosis factor-related apoptosis-inducing ligand (TRAIL) and paclitaxel have cooperative in vivo effects against glioblastoma multiforme cells. Mol. Cancer Ther. 8: 32853295. http://dx.doi.org/10.1158/1535-7163.MCT-09-0415

Genetics and Molecular Research 15 (4): gmr15048876 
Hanahan D and Weinberg RA (2000). The hallmarks of cancer. Cell 100: 57-70. http://dx.doi.org/10.1016/S0092$\underline{8674(00) 81683-9}$

Himeji D, Horiuchi T, Tsukamoto H, Hayashi K, et al. (2002). Characterization of caspase-8L: a novel isoform of caspase-8 that behaves as an inhibitor of the caspase cascade. Blood 99: 4070-4078. http://dx.doi.org/10.1182/blood. V99.11.4070

Kang Z, Goldstein SD, Yu Y, Meltzer PS, et al. (2015). Caspase-8 expression is predictive of tumour response to death receptor 5 agonist antibody in Ewing's sarcoma. Br. J. Cancer 113: 894-901. http://dx.doi.org/10.1038/bjc.2015.298

Kavanagh E, Burguillos MA, Carrillo-Jimenez A, Oliva-Martin MJ, et al. (2015). Deletion of caspase-8 in mouse myeloid cells blocks microglia pro-inflammatory activation and confers protection in MPTP neurodegeneration model. Aging (Albany NY) 7: 673-689. http://dx.doi.org/10.18632/aging.100805

Na IK, Lu SX, Yim NL, Goldberg GL, et al. (2010). The cytolytic molecules Fas ligand and TRAIL are required for murine thymic graft-versus-host disease. J. Clin. Invest. 120: 343-356. http://dx.doi.org/10.1172/JCI39395

Ottaviani G and Jaffe N (2009). The epidemiology of osteosarcoma. Cancer Treat. Res. 152: 3-13. http://dx.doi. org/10.1007/978-1-4419-0284-9 1

Piras V, Hayashi K, Tomita M and Selvarajoo K (2011). Enhancing apoptosis in TRAIL-resistant cancer cells using fundamental response rules. Sci. Rep. 1: 144. http://dx.doi.org/10.1038/srep00144

Polanski R, Vincent J, Polanska UM, Petreus T, et al. (2015). Caspase-8 activation by TRAIL monotherapy predicts responses to IAPi and TRAIL combination treatment in breast cancer cell lines. Cell Death Dis. 6: e1893. http:// dx.doi.org/10.1038/cddis.2015.234

Qi L, Ren K, Fang F, Zhao DH, et al. (2015). Over expression of BCL2 and low expression of caspase 8 related to TRAIL resistance in brain cancer stem cells. Asian Pac. J. Cancer Prev. 16: 4849-4852. http://dx.doi.org/10.7314/ APJCP.2015.16.12.4849

Shabanzadeh AP, D’Onofrio PM, Monnier PP and Koeberle PD (2015). Targeting caspase-6 and caspase-8 to promote neuronal survival following ischemic stroke. Cell Death Dis. 6: e1967. http://dx.doi.org/10.1038/cddis.2015.272

Sharifi S, Barar J, Hejazi MS and Samadi N (2015). Doxorubicin changes Bax /Bcl-xL ratio, caspase-8 and 9 in breast cancer cells. Adv. Pharm. Bull. 5: 351-359. http://dx.doi.org/10.15171/apb.2015.049

Soria JC, Smit E, Khayat D, Besse B, et al. (2010). Phase 1b study of dulanermin (recombinant human Apo2L/TRAIL) in combination with paclitaxel, carboplatin, and bevacizumab in patients with advanced non-squamous non-small-cell lung cancer. J. Clin. Oncol. 28: 1527-1533. http://dx.doi.org/10.1200/JCO.2009.25.4847

Wafa H and Grimer RJ (2006). Surgical options and outcomes in bone sarcoma. Expert Rev. Anticancer Ther. 6: 239-248. http://dx.doi.org/10.1586/14737140.6.2.239

Woods DC, Alvarez C and Johnson AL (2008). Cisplatin-mediated sensitivity to TRAIL-induced cell death in human granulosa tumor cells. Gynecol. Oncol. 108: 632-640. http://dx.doi.org/10.1016/j.ygyno.2007.11.034

Yang X and Thiele CJ (2003). Targeting the tumor necrosis factor-related apoptosis-inducing ligand path in neuroblastoma. Cancer Lett. 197: 137-143. http://dx.doi.org/10.1016/S0304-3835(03)00093-4

Zhao J, Lu Y and Shen HM (2012). Targeting p53 as a therapeutic strategy in sensitizing TRAIL-induced apoptosis in cancer cells. Cancer Lett. 314: 8-23. http://dx.doi.org/10.1016/j.canlet.2011.09.040

Genetics and Molecular Research 15 (4): gmr15048876 